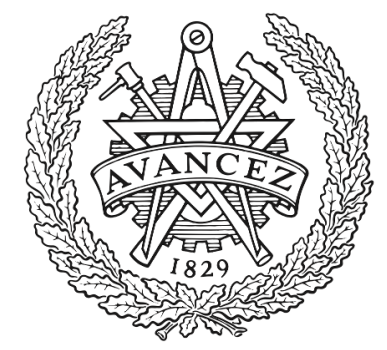

CHALMERS

UNIVERSITY OF TECHNOLOGY

\title{
A coupled approach for vehicle brake cooling performance simulations
}

Downloaded from: https://research.chalmers.se, 2023-04-26 14:14 UTC

Citation for the original published paper (version of record):

Vdovin, A., Gustafsson, M., Sebben, S. (2018). A coupled approach for vehicle brake cooling performance simulations. International Journal of Thermal Sciences, 132: 257-266.

http://dx.doi.org/10.1016/j.ijthermalsci.2018.05.016

N.B. When citing this work, cite the original published paper. 
This is a preprint version of the following paper:

A. Vdovin, M. Gustafsson, S. Sebben, "A coupled approach for vehicle brake cooling performance simulations", International Journal of Thermal Sciences, Vol. 132, pp 257266, 2018, https://doi.org/10.1016/i.ijthermalsci.2018.05.016.

Being a preprint and not the final accepted manuscript, this version does not include the corrections made to the paper after the review process and therefore it is slightly different from the published journal article. The readers are advised to follow the DOI link to access the published version online.

(C) 2018. This manuscript version is made available under the CC-BY-NC-ND 4.0 license http://creativecommons.org/licenses/by-nc-nd/4.0/

\title{
A coupled approach for vehicle brake cooling performance simulations
}

\author{
Alexey Vdovin ${ }^{1}$, Mats Gustafsson², Simone Sebben ${ }^{3}$ \\ ${ }^{1}$ Corresponding author; Department of Mechanics and Maritime Sciences, Chalmers University \\ of Technology, 41296 Gothenburg, Sweden; alexey.vdovin@chalmers.se; \\ ${ }^{2}$ Braking Department, Volvo Car Corporation, Torslanda PVV2:1, Gothenburg 405 31, Sweden; \\ mats.r.gustafsson@volvocars.com; \\ ${ }^{3}$ Department of Mechanics and Maritime Sciences, Chalmers University of Technology, 41296 \\ Gothenburg, Sweden; simone.sebben@chalmers.se.
}

\section{Abstract}

Advances of CFD methods together with the constant growth of computer capacity enables simulations of complex coupled fluid and thermal problems. One such problem is the evaluation of brake cooling performance. The brake system is a critical component for passenger vehicles and ensuring correct brake operation under all possible load scenarios is a safety issue. An accurate prediction of convection, conduction and radiation heat fluxes for such a complicated system is challenging from modelling as well as numerical efficiency perspectives.

This study describes a simulation procedure developed to numerically predict brake system component temperatures during a downhill brake performance test. Such tests have stages of forced and natural convection, and therefore, the airflow is influenced by the temperature changes within the system. For the numerical simulation, a coupled approach is utilised by combining aerodynamic and thermal codes. The aerodynamic code computes the convective heat transfer 
using a fully-detailed vehicle model in the virtual wind tunnel. The thermal code then uses this data and combines it with conduction and radiation calculations to give an accurate prediction of the component temperatures, which are subsequently used for airflow recalculation. The procedure is described in considerable detail for most parts of the setup.

The calculated temperature history results are validated against experimental data and show good agreement. The method allows detailed investigations of distribution and direction of the heat fluxes inside the system, and of how these fluxes are affected by changes in material properties as well as changes in parts within or outside the brake system. For instance, it is shown that convection and especially convection from the inner vanes is the main contributor for the heat dissipation from the brake disk. Finally, some examples of how changing the vehicle design affects the brake cooling performance are also discussed.

Keywords: Brake cooling, Alpine Descent, CFD, Brake Thermal Management

\section{Introduction}

The brake system is one of the most critical components of a vehicle since it converts the vehicle kinetic, or potential, energy into heat, allowing the vehicle to decelerate or stop when needed. Overheating of the brake system components is a safety issue that can cause serious problems such as decreased friction coefficients, i.e. brake fading. Moreover, such overheating can result in generating brake judder and/or brake squeal, increasing wear, thermal cracking and even brake fluid vaporization [1, 2]. Furthermore, other wheel suspension parts, like wheel cover or tyre, can also be affected by high temperatures, especially during thermal soak (natural convection) [3, 4]. In order to avoid these problems, the brake system should be appropriately dimensioned and designed to ensure the correct operation under various braking scenarios.

Historically, this has been achieved by extensive experimental testing of the brake components using various test benches and full vehicle testing. However, in recent decades, the constantly growing computation capacity has led to significant advances in simulation methods. Computer Aided Engineering (CAE) methods are not only cheaper but also provide more detailed information about heat dissipation from and within parts, and heat transfer coefficients, and rates. In addition, CAE can be used during early stages of the vehicle development when physical prototypes may be unavailable or when many variants are being developed.

Full-scale simulations of a brake system can be done with different levels of complexity. Whereas simple simulations can focus on a single or several ventilation channels inside the brake disc [5, 6]; or a complete brake disc and selected parts around it [7, 8, 9, 10]; more complex simulations include the entire vehicle $[11,12]$. As shown by Stephens et al., the latter allows better representation of the on-road conditions [13], but requires at the same time much more data about the components and their relative material properties. While most numerical simulations focus either on computing convection heat transfer coefficients from a Computational Fluid Dynamics (CFD) point of view, or on conduction modelling through the solid parts, a significant step was 
taken $[14,15,16]$ by coupling aerodynamic and thermal codes. In such cases, the aerodynamic code is responsible for the computation of the convective heat transfer rates whereas the thermal code handles the conduction and the radiation behaviour. Considering the convection heat transfer, the flow around the rotating disc is often considered the same, and independent of, the surface temperatures. However, if the thermal soaking process is taken into account, the airflow is then driven by the buoyancy forces and is then dependent on the surface temperatures [17].

As simulation methods develop, more and more effort is being put into replacing long and expensive physical testing of brake systems. These simulations need to not only have very good geometrical representation of vehicle parts but also good material data. The present paper aims at describing the implemented coupled method for a simulation of a 30-minute downhill brake test.

\section{Driving cycle and the test object description}

There are a number of different driving cycles that are commonly used for brake cooling performance tests. The coupled procedure described in this paper is developed to numerically simulate one of them: the Alpine Descent brake test. The sketch in Figure 1 shows the real Alpine Descent test, which consists of two phases:

1) downhill driving at $10 \mathrm{~m} / \mathrm{s}$ with more or less constant drag braking (heat-up phase) on a slope of about $10 \%$ for about 20 minutes;

2) thermal soaking, when the vehicle stands still and the heat dissipates from the disc into the brake system and environment (cool-down phase) for about 15-20 minutes.

During the experiment, the focus is on temperatures of the brake disc and the brake fluid. In order to consider the worst-case scenario for the fluid: the brake disc and brake pads are kept in constant contact with the disc even during the cool-down phase.

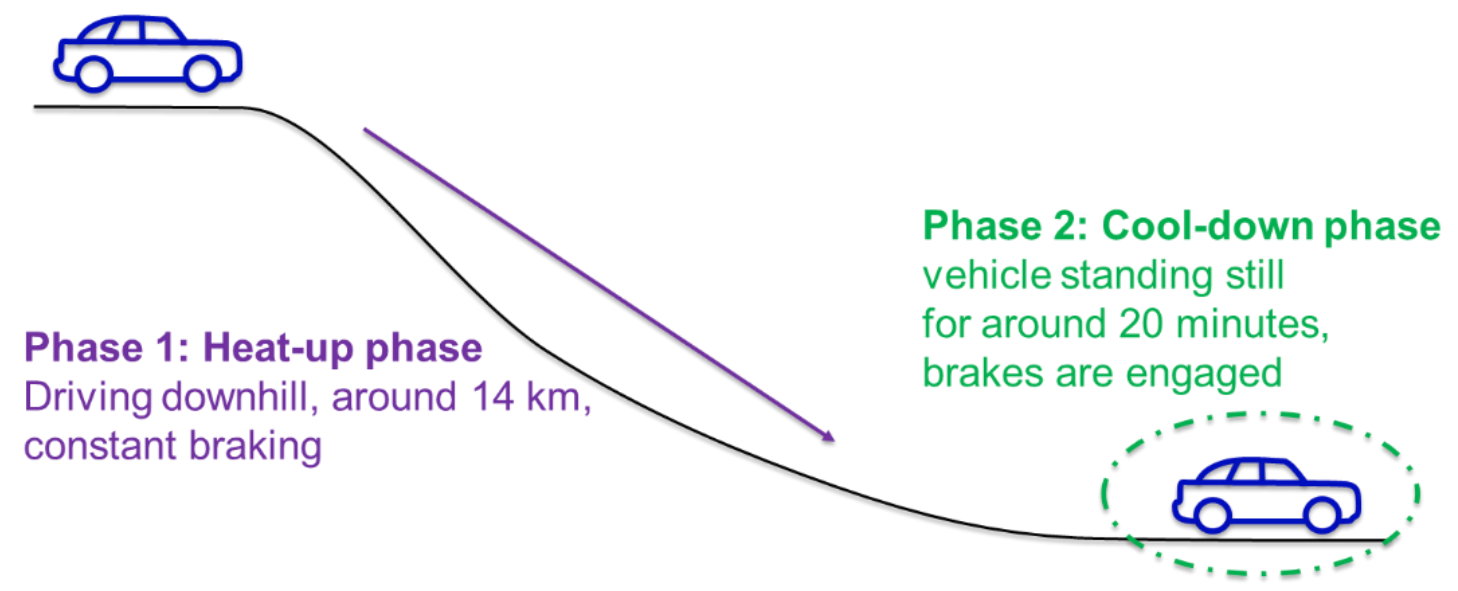

Figure 1. Sketch of the studied Alpine descent driving cycle

To improve development efficiency, simplified variants of this test have been devised. The replacement tests can be conducted either on a level test track were the braking vehicle is being pushed by a second car, or in a wind tunnel. The wind tunnel variant is more expensive but it 
provides a much more controlled test environment with fixed air temperature and speed, no weather complications, and constant braking force. Consequently, in order to reduce uncertainties in the simulation results inherent to experimental testing, the present computational procedure replicates laboratory experiment performed in a wind tunnel.

A full-size production vehicle was used as a test object for both simulations and wind tunnel experiments. From previous experience, it was known that due to underhood packaging, the righthand wheelhouse of the specific vehicle experienced higher temperatures. Therefore, the experiment and modelling focused only on this side of the vehicle.

\section{Numerical method description}

The following procedure is based on the coupling of a CFD code with a Finite Element Analysis (FEA) thermal simulation. StarCCM+ is used for calculation of the flow and convective heat transfer, TAITherm is the main thermal solver, and CoTherm works as a coupling software that allows easy setup and control over data exchange between the two solvers.

The Alpine descent braking scenario dictates the approach that needs to be taken for recalculation of the airflow around the brake disc and hence the convective heat fluxes. While for high velocities the assumption of the surface heat transfer coefficients being independent of the surface temperatures can be taken, this is not true for the alpine descent since the velocities are not high enough. Moreover, during the cool-down phase, the flow is completely driven by the buoyancy forces and thus highly dependent on component surface temperatures. In this study, the airflow and convective heat fluxes are recalculated several times and linearly interpolated inbetween the recalculations for both heating-up and cooling-down phases.

The description of the aerodynamic model and the thermal models as well as the coupling process are presented and discussed below. The two phases of the test (heat-up and cool-down) are quite different from a computer simulation prospective and are therefore defined by two aerodynamic and two thermal setups.

\subsection{Aerodynamic model}

In order to calculate the surface convective heat fluxes for the parts of the brake system a CFD simulation needs to be prepared. A fully-detailed vehicle model is positioned in the virtual wind tunnel according to Figure 2. It is important that the vehicle geometry is well represented in order to capture the flow around the parts of interest. On the other hand, since the mapping between 
codes is based on the coordinates there is no need to have matching mesh or matching surface names between them.

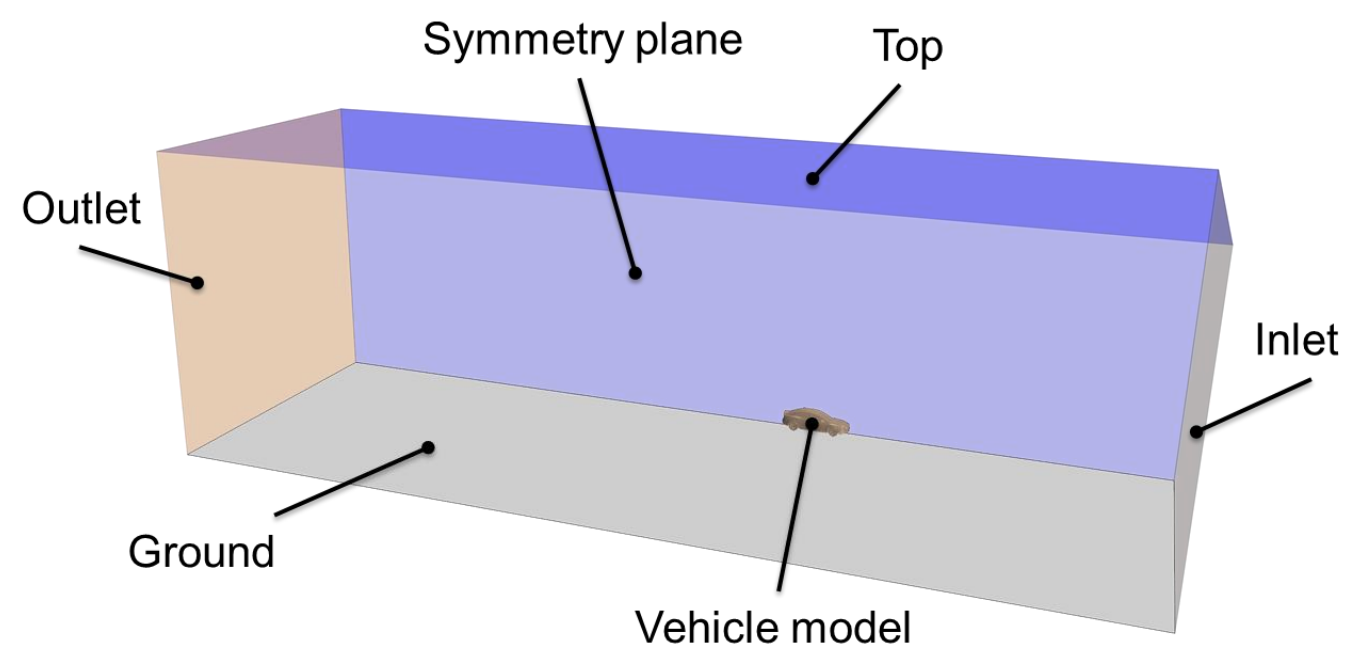

Figure 2. CFD model of the vehicle in the virtual wind tunnel

To decrease the mesh count while maintaining mesh-independency of results, only the right half of the vehicle is simulated with the second half imitated using a symmetry plane. The virtual tunnel is 60 metres long, 40 metres wide and 20 metres tall to ensure that there is no unwanted interference from the tunnel boundary conditions. The mesh is predominantly hexahedral with refinements concentrated around the front wheelhouse since it is the area of main interest. The minimum surface cell size is $0.7 \mathrm{~mm}$ for the inner vanes of the brake disc and the final mesh count, including prism layers on all of the surfaces, is around 30 million volume cells. This number was achieved after a mesh independence study and is a good compromise between accuracy and computational performance.

The same volume mesh is used for both heat-up and cool-down phases of the test with the differences being in the boundary conditions setup. For the heat-up phase, the virtual wind tunnel is set-up with a $10 \mathrm{~m} / \mathrm{s}$ velocity-inlet, corresponding ground and wheel rotation velocities as well as pressure-outlet condition for the outlet. For the cool-down, the ground movement and wheel rotation are set to zero; the wind tunnel inlet, outlet and the walls are simulated as stagnation inlets, while the top is assigned a pressure outlet boundary condition.

The simulations are performed using steady-state Reynolds-Averaged Navier-Stokes approach with ground movement and wheel rotation simulated using moving walls boundary conditions and the multiple reference frame approach. These are normal practices in aerodynamic simulations of vehicles [18]. Underhood heat-exchangers are modelled as porous media regions; energy and gravity models are used to account for temperature gradients in the air and their influence on the airflow.

The parts of the wheel and brake system that are supposed to be mapped with the surface temperatures during coupling process are specifically named and the rest of the vehicle surfaces are assigned as adiabatic walls. 


\subsection{Thermal model}

For the thermal model, it is important to include all of the parts that have an influence on the dissipation of energy from the brake disc. The parts that are used can be seen in Figure 3 and they include the following: 1 - tire; 2 - rim (with rim saddle highlighted in cyan); 3 - brake disc (with contact surfaces and inner vanes separated for easier setup); 4 - dust shield; 5 - wheel hub; 6 upright (knuckle); 7 - caliper sliding frame; 8 - caliper body with piston, bushings and brake fluid hose; 9 - brake pads with shims and back plates.

The mesh requirements for the thermal code are not as strict as for the aerodynamic simulations, so all of the surfaces are meshed with cell size up to $20 \mathrm{~mm}$ while making sure that the important geometrical features are captured. The volume finite element mesh is predominantly tetrahedral with at least 3-5 volume elements for the thickness of thin parts. The brake shield, being a very thin part, is simulated using shell elements.

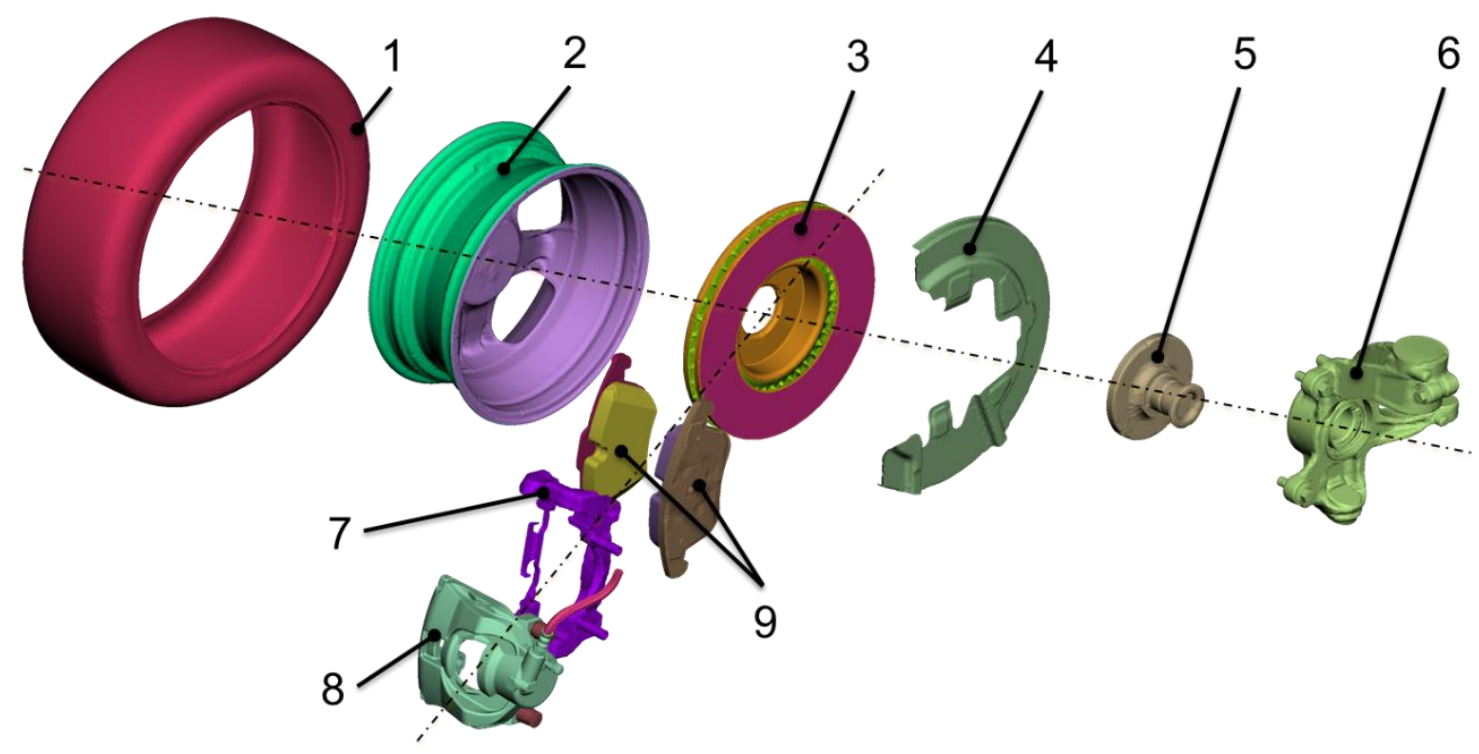

Figure 3. Brake system model for the thermal simulation (exploded view)

One of the most vital parameters to setup in this procedure is the material thermal properties of all of the represented parts. Ideally, the specific heat and thermal conductivity should be represented as temperature dependent curves at least for the brake disc and the brake pads, where the temperature can change significantly during the driving cycle. For the current procedure, material properties and emissivity of surfaces were measured using professional equipment or obtained from the component manufactures.

Two different approaches were considered and investigated for the simulation of the brake fluid. The first one uses a fluid node with all brake fluid mass concentrated at one point and conductive connections set up to the corresponding surfaces of the piston and caliper. This leads to one temperature at any point inside the fluid volume. The second approach is to wrap the fluid volume from inside and assign it as a distributed mass with fluid material properties. The latter option 
allows temperature gradients inside the fluid and even though the convective flows inside the brake fluid chamber are still ignored, this approach was considered more accurate and was therefore used in this procedure.

Using the imported convective heat transfer coefficients from the CFD simulation the thermal code handles the three forms of heat transfer: convection, conduction and radiation. Even so, each has some special setup required for the brake cooling application:

- For convection, special attention is required to the part surfaces not participating in the heat conduction between parts and not simulated in the aerodynamic simulation, such as the inner side of the tyre, rim saddle etc. Such surfaces are excluded from the CFD data mapping.

- For radiation, a surface-to-surface model is used, which requires a special setup for the rotating brake disc, when the rotating surfaces on the sides of the disc are modelled as large radiation patches to avoid local cold point formation.

- For conduction, the main difficulty is the energy input between the disc surfaces and the pad surfaces during the heat-up phase. These surfaces are connected in the model using generic thermal links with the heat flux applied to a virtual node in between them. The amount of energy added to the system is estimated based on the braking force recorded during wind tunnel tests, and it is equally distributed between the contact faces on each side of the disc. If other vehicles were to be considered, the energy input would need to be adjusted both in the wind tunnel experiment and in the simulation procedure corresponding to the new vehicle mass. The setup allows not only correct surfaces participating in the heat transfer, but also to have heat fluxes into brake pads and brake disc changing over time based on the material properties and temperatures of the corresponding parts.

The mesh used for the thermal model has around 3 million cells that are predominantly hexahedral, since they are better than tetrahedral ones for internal conduction through the material [19]. The wheelhouse environment is represented by a bounding box with a temperature of $20^{\circ} \mathrm{C}$. The time step size is decided by the solver using an adaptive algorithm with a maximum step size of 10 seconds.

\subsection{Coupling procedure}

A simplified coupling process is presented in Figure 4. The CFD code is used to calculate convective heat transfer coefficients on the surfaces of the parts involved in the coupling process as well as the air temperatures next to the surfaces. These are the values required to compute convective heat transfer from the surfaces of different parts. At the same time, the thermal code calculates all three modes of heat transfer and computes the changes in temperatures occurring inside parts over a time period. After this, the thermal code returns surface temperatures to the CFD solver, allowing recalculation of the flow field around brake system parts. 


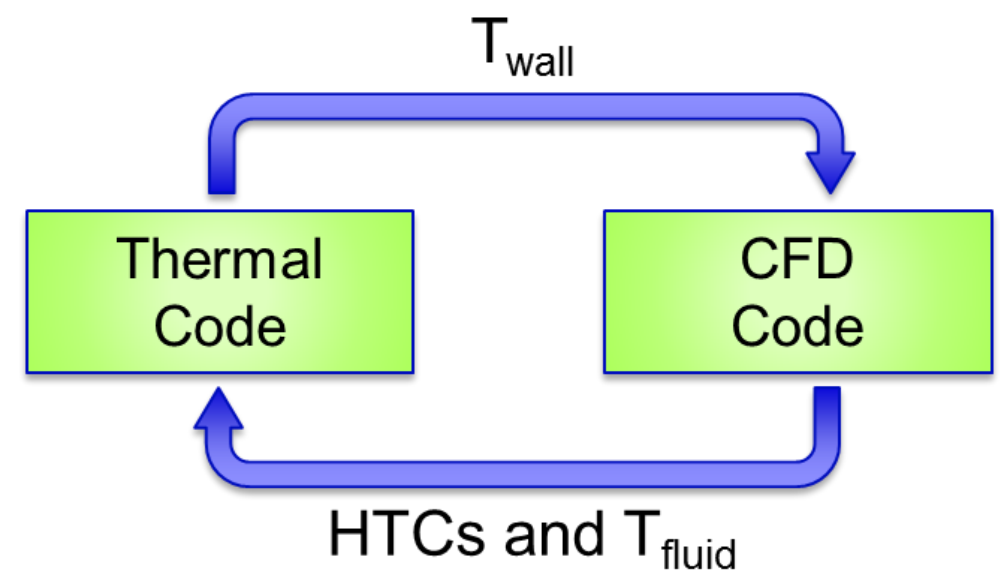

Figure 4. A simplified example of a coupling process

In reality, the process is somewhat more complicated, since the convective heat fluxes are changing with time and should not be considered constant. The procedure contains two loops, one of which is nesting inside the other one. The outer loop is advancing the solution forward by dividing simulation time into time intervals and switching to the next interval only when the convergence of the inner loop on the current interval is achieved. The inner (nested) loop of the simulation is presented in Figure 5. This loop starts from assigning constant convection parameters for the entire interval, and then it runs the thermal solution and recalculates the convective parameters for the end of the interval. Afterwards, the convection parameters are interpolated between the beginning and the end of the current interval, and the thermal solution is repeated. This iterative process continues until convergence of the surface temperatures at the end of the time interval is achieved.

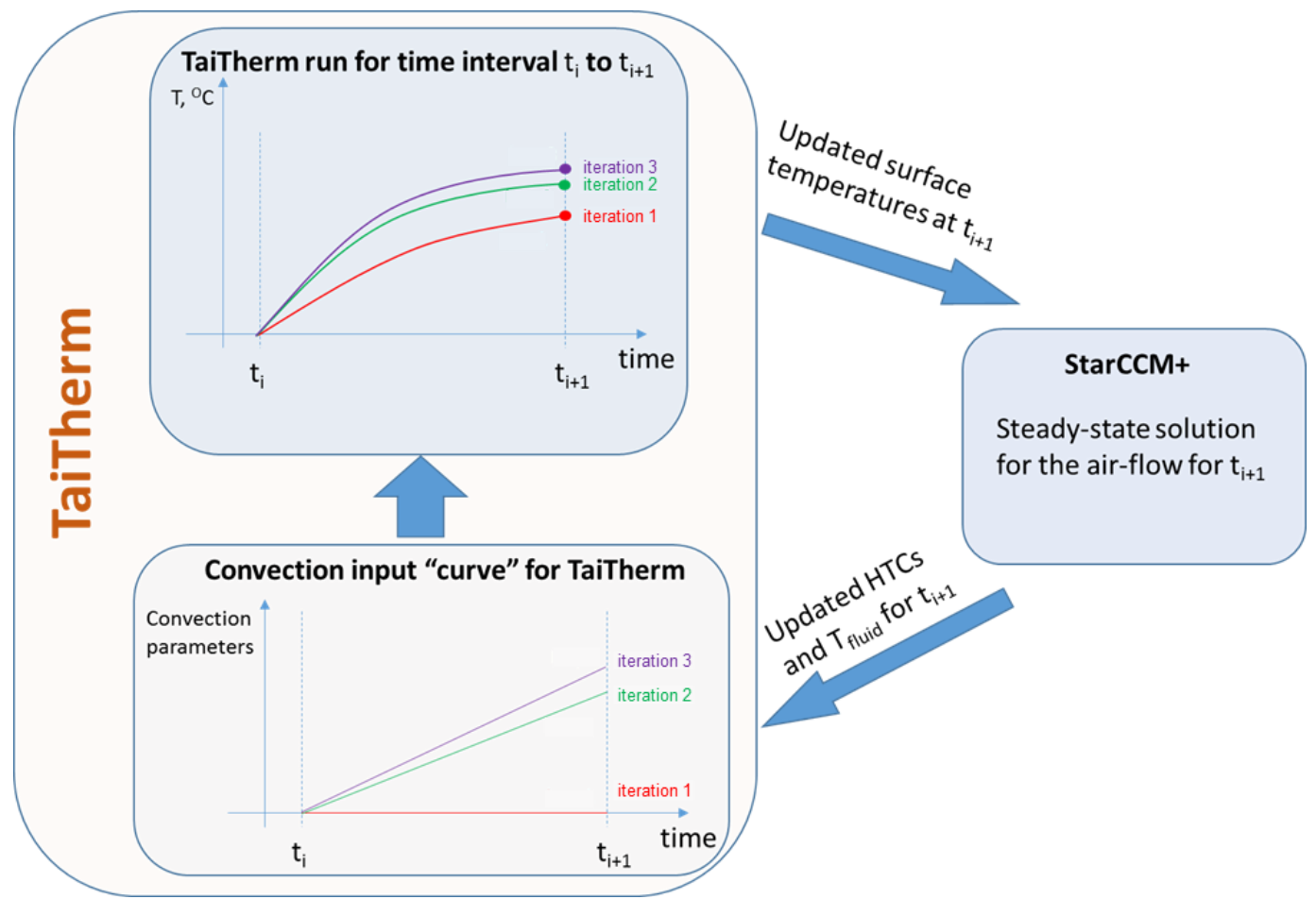

Figure 5. Coupling process and convective input recalculation inside the inner loop 
As previously stated, the coupling is based on the coordinates in space and not on the part names; therefore, slight differences in CFD and thermal models are acceptable. This allows a coarser mesh for the thermal simulation, which is desirable for shorter computational times.

The switch between heat-up and cool-down models happens in the middle of the process (in accordance with the alpine descent test scenario it happens at the 1410 seconds mark) with the temperature gradients inside parts and on their surfaces being mapped from the last step of the heat-up simulation to the first step of the cool-down simulation. After that, the CFD simulation runs until the convergence of the flow is achieved and the convective heat fluxes are calculated. Then, the process continues exactly as in the heat-up phase. The convergence of the CFD solution on every step of the process is ensured by two separate stopping criteria: one limiting the minimum extra iterations to run, and one confirming asymptotic behaviour of the air temperatures next to the brake disc.

The whole process takes roughly 2500 core hours for one full Alpine descent cycle simulation.

\section{Test cases}

In order to validate the procedure and to study the effects of different component designs on the brake cooling performance, four different test cases were simulated. The baseline case (Case 0 ) replicates the test performed in the wind tunnel with the CAD model having detailed representation of the real test vehicle. This case is used for validation of the method and for general investigations of heat fluxes and temperature distributions for different parts.

In addition to the baseline case, the following configurations were studied:

- Case 1: closed rims design, as in Figure 6. This configuration is advantageous from the aerodynamic drag perspective but it is usually not acceptable for brake cooling.

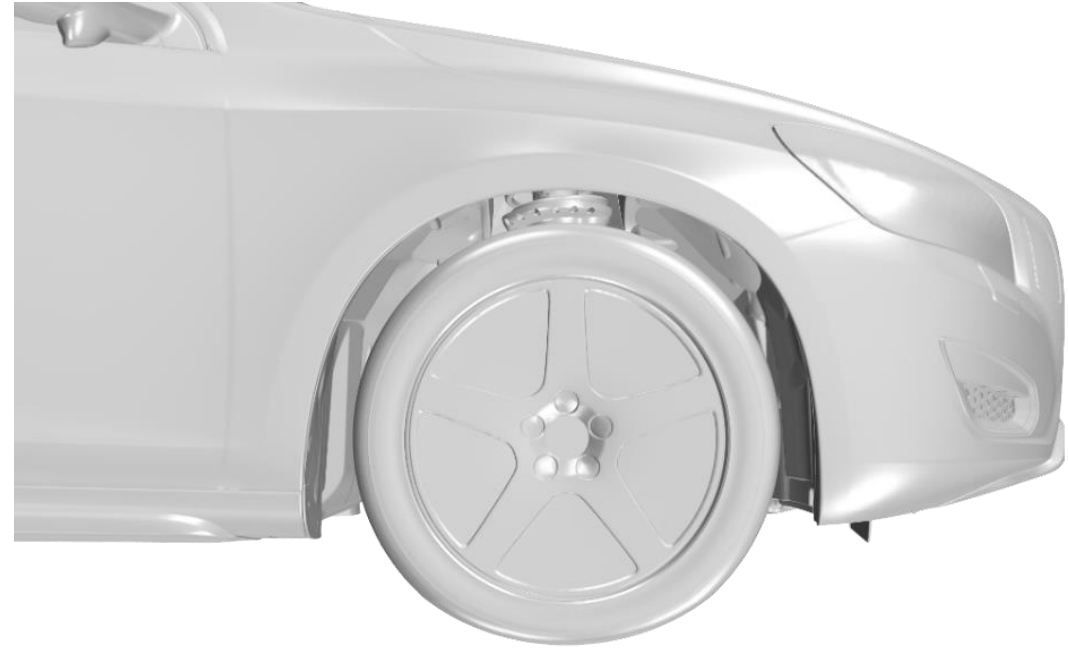

Figure 6. Closed rims design configuration 
- Case 2: blocked ventilation vanes of the brake disc, Figure 7. In this case, the airflow through the disc inner vanes is blocked, keeping the vanes themselves in place and maintaining same mass and therefore same thermal inertia of the disc.

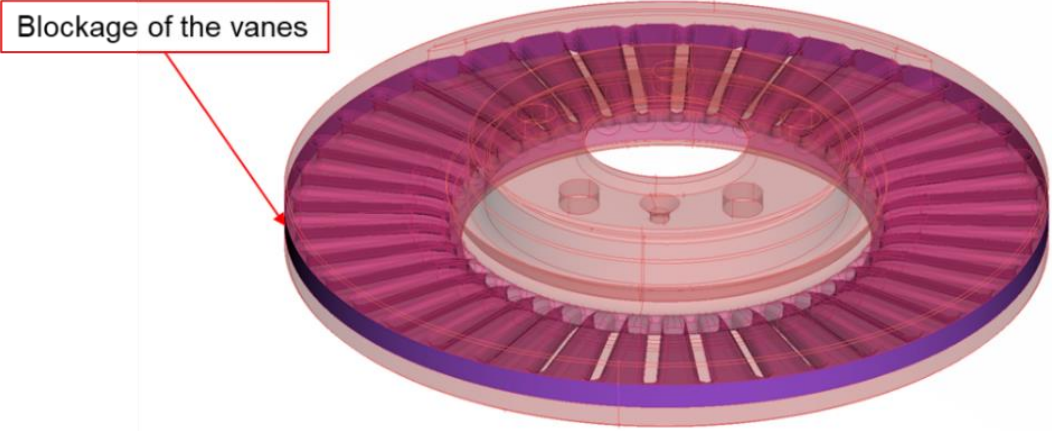

Figure 7. A baffle surface preventing the airflow for blocked ventilation vanes design

- Case 3: removed brake dust shield. Changing dust shield design (part 4 in Figure 3), is another way to affect the cooling performance and the extreme case of having no dust shield is a way to see the possible potential.

\section{Experimental setup and model validation}

\subsection{Experiment description}

For the experimental part, the vehicle was tested in a full-scale closed-circuit aerodynamic wind tunnel at Volvo Car Corporation. Further details about the tunnel and its operational conditions can be found in the work by Sterneus [20]. The vehicle was positioned on the dyno rollers of the wind tunnel, as seen in Figure 8, and driven for 23 minutes(1410 seconds) corresponding to a 14 $\mathrm{km}$ drive. The vehicle and air velocities were maintained at $10 \mathrm{~m} / \mathrm{s}$ with a constant braking force of $750 \mathrm{~N}$ for the heat-up phase. For the second part of the test, the cool-down phase, the vehicle was standing still with no oncoming airflow and the temperatures of the hot brake disc were dissipating into the brake system and to the surroundings. During this phase, the brakes were also engaged providing conduction between the brake discs and the brake pads to obtain the worst-case scenario for the brake fluid. 


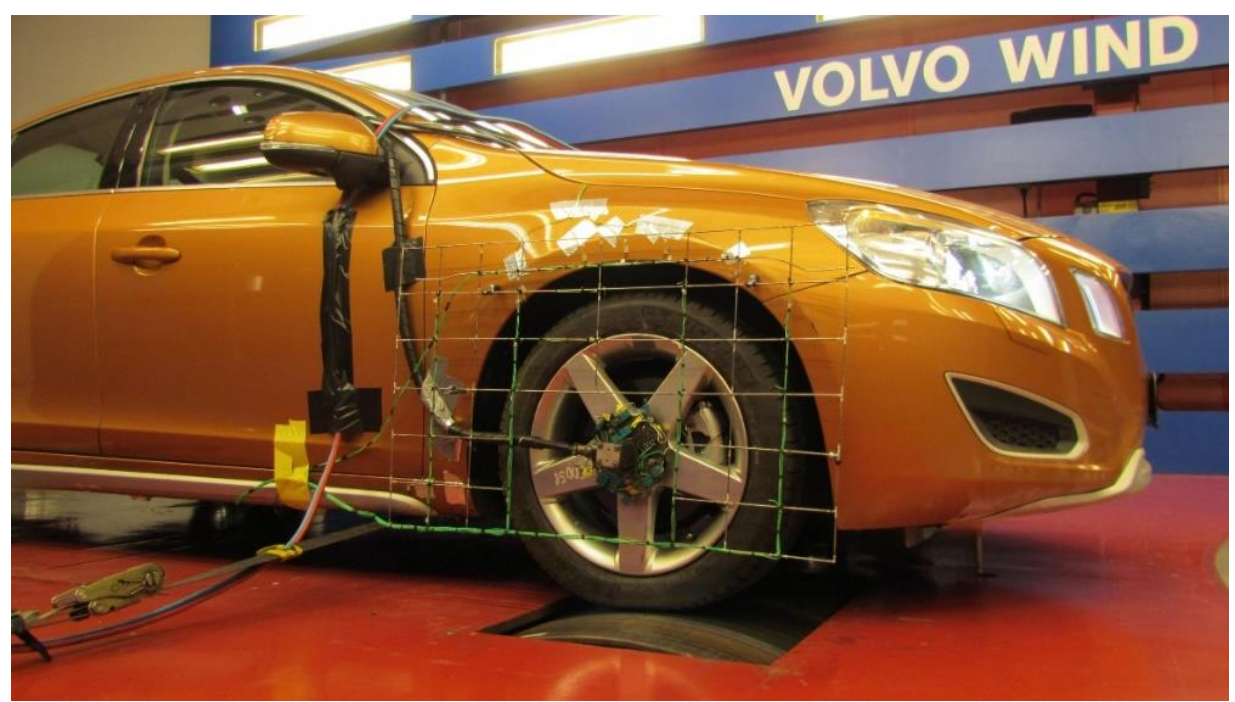

Figure 8. Vehicle positioned in the wind tunnel for the simulated Alpine Descent test

The wheel was equipped with a slip-ring connector in order to have the time history of the eight thermocouples on the different parts of rotating brake disc: four on the piston (inboard) side and four on a finger (outboard) side, see Figure 9 for exact positioning. Consequently, the points were named 1-4F (finger) and 1-4P (piston). The brake pad's position at which the wheel was stopped for the cool-down phase can also be seen. Additionally, 120 thermocouples were used to obtain temperature history of different parts and the air next to them. To measure the temperature of the brake fluid inside the caliper a modified bleeding screw was utilized.

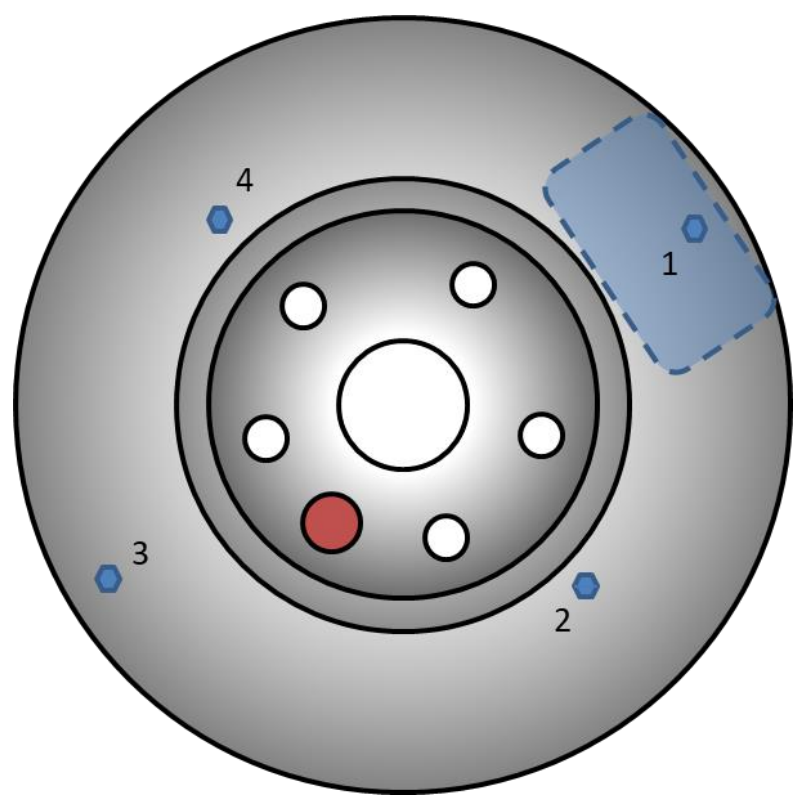

Figure 9. Positions of the brake disc temperature probes and the brake pads location during the soaking phase 


\subsection{Comparison of numerical and experimental results}

The consistency of the experimental results even in the wind tunnel test is far from being perfect because of the hotspot formation on the brake disc. Indeed, the surface temperatures at the same radius of the same side of the disc (e.g. point 2 and point 4 in Figure 9) can easily vary by more than 100 degrees. Moreover, since higher local temperatures lead to increased thermal expansion and increased wear, these hot spots move with every new load cycle [21].

Figure 10 presents the comparison of brake disc temperatures for the outer radius of the disc from the finger side. During heat-up phase (0-1410s), the results correlate quite well, especially keeping in mind that the energy input to the system due to friction is difficult to estimate. For the cool-down phase (1410-3000s), a slight over-prediction of temperatures can be observed. The difference between points 1 and 3 is their position relative to the brake pad during the cool-down phase. It can be seen that initially the disc cools faster under the pads (point 1F) due to conduction of the heat to the pads and further into the system, but later the effect is reversed since this area is less affected by convection. Considering all unknowns, the results even for the cool-down phase are quite satisfactory.

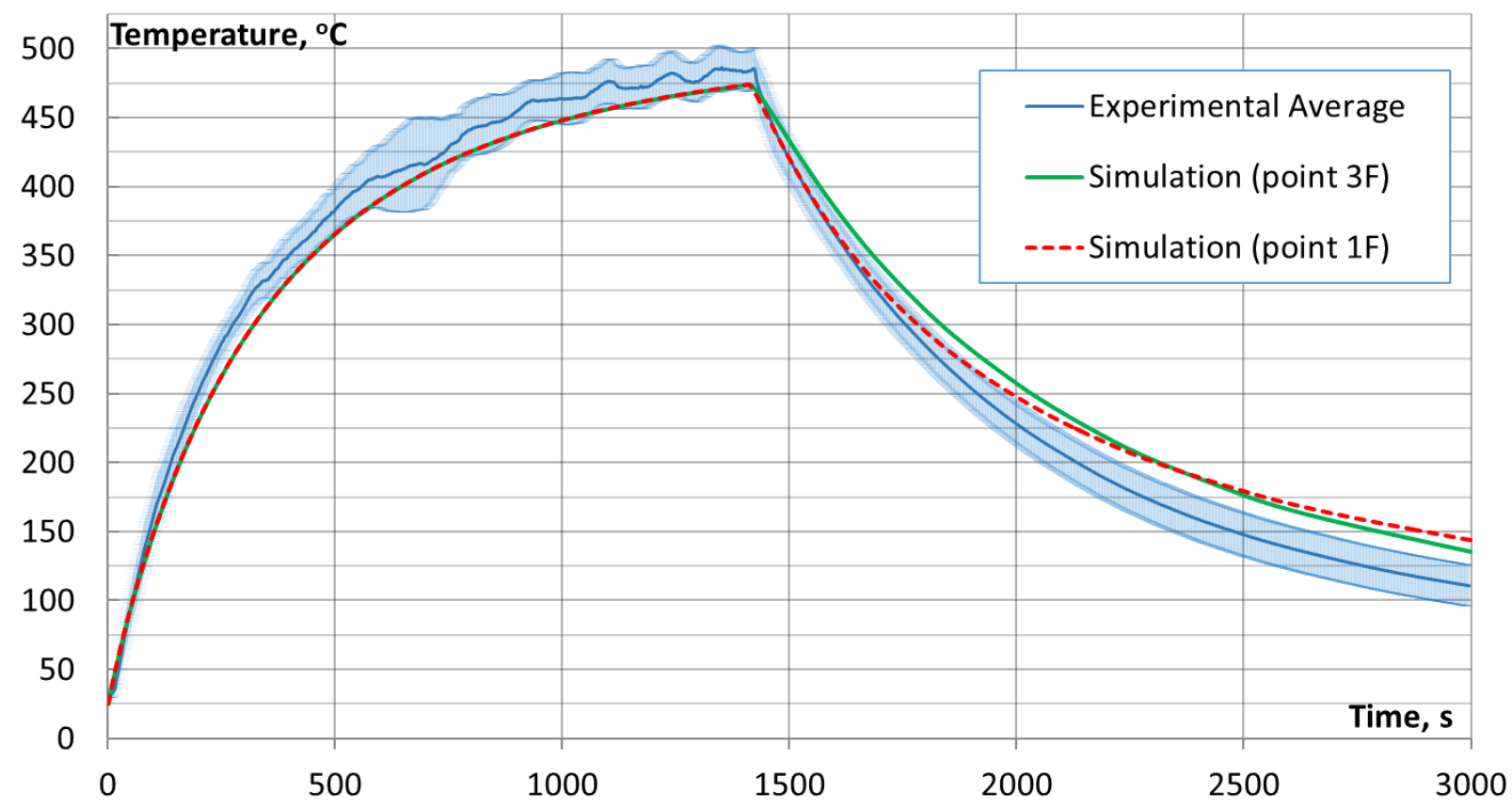

Figure 10. Temperature history for two points of the brake disc surface

Figure 11 shows a comparison for the brake fluid temperatures. The heat-up phase again shows a very good correlation between the experiment and the simulation results, though for the cooldown phase an under-prediction of temperatures can be seen. Nevertheless, the difference is acceptable $\left(10^{\circ} \mathrm{C}\right.$ at most) and the general behaviour is well captured, making possible comparisons of different brake system designs against the reference. 


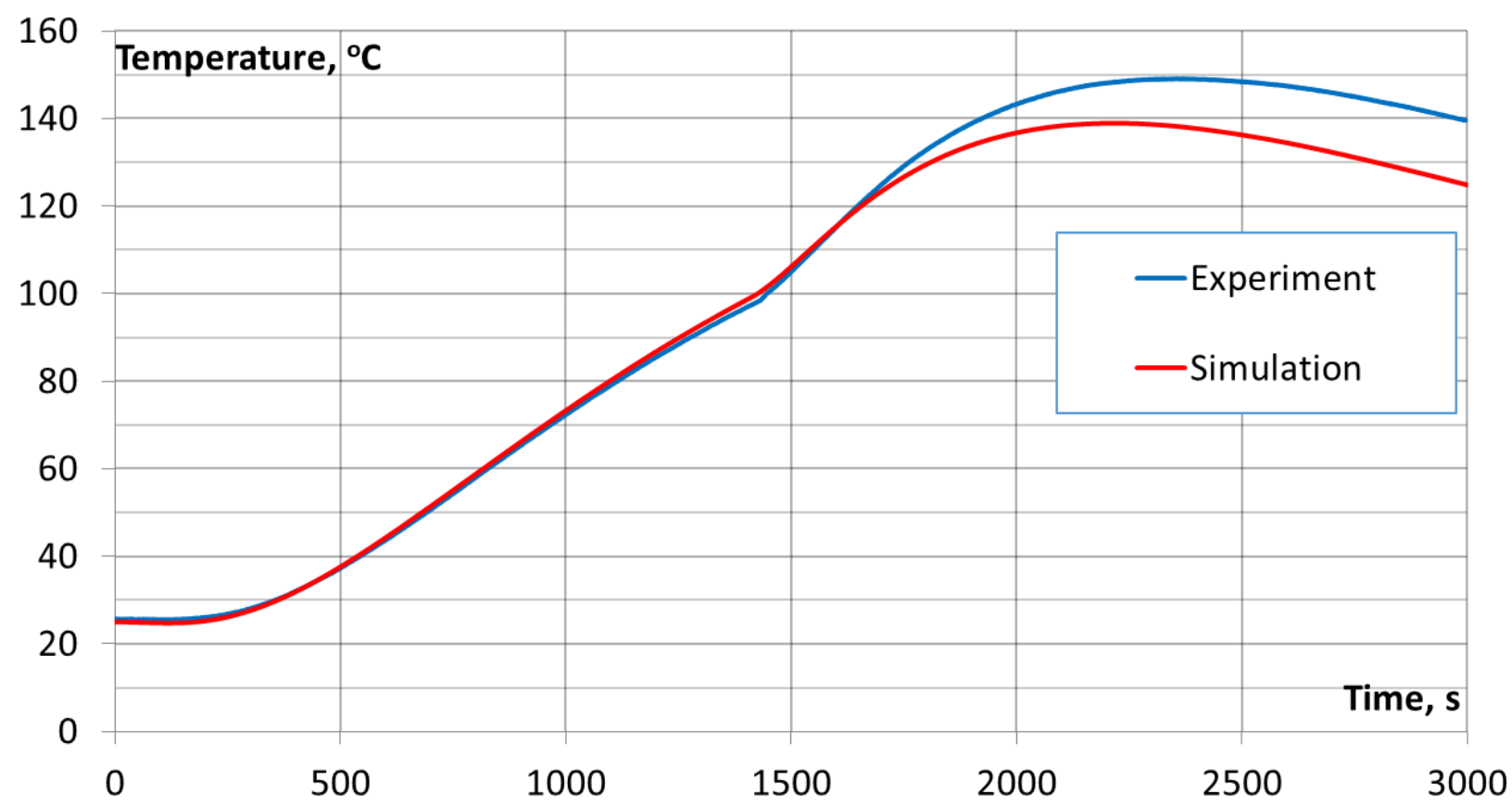

Figure 11. Comparison of the experimental and simulation results for the brake fluid temperature

\section{Results and discussions}

In this section, the simulation results for the baseline model (case 0 ) are firstly analysed in more detail, then cases 1 to 3 are compared and discussed.

\subsection{Baseline model}

The coupled simulation procedure allows very detailed analyses of the temperature gradients inside different parts and the flow around them. Figure 12 shows temperature gradients in the thermal model at the end of heat-up phase. The disc is obviously the hottest part with maximum temperature reaching $490^{\circ} \mathrm{C}$, which is higher than in the exported points $1 \mathrm{~F}$ and $3 \mathrm{~F}$, see Figure 9. Another interesting observation is that the wheel hub and the wheel rim are also heating up above $100^{\circ} \mathrm{C}$, which again correlates well with the experimental data.

The convective airflow at the beginning of the cool-down phase is shown in Figure 13. The air is heated by the brake disc surfaces and the other surfaces around it. Due to buoyancy forces, it accelerates and escapes the wheelhouse mostly on top of the wheel arch, but also goes into the engine bay. 


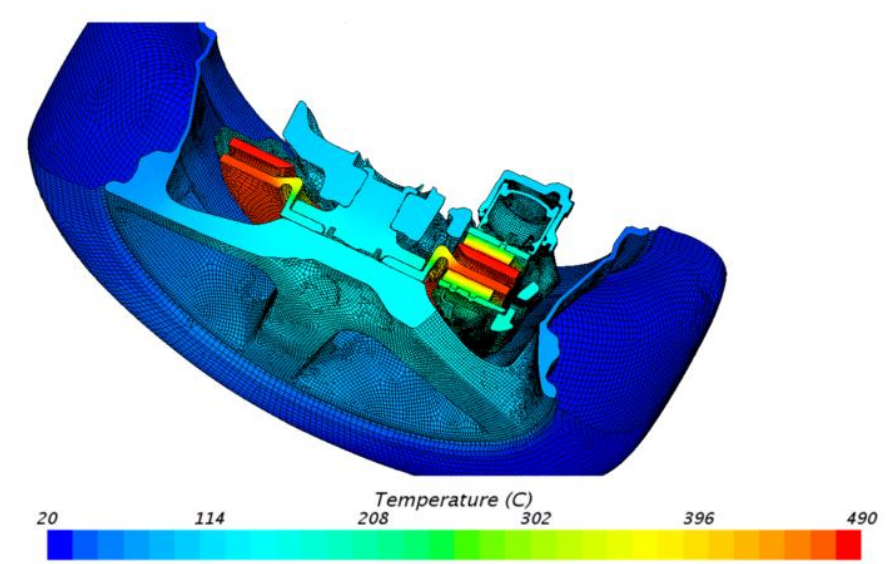

Figure 12. Temperature gradients in the system after the heat-up phase

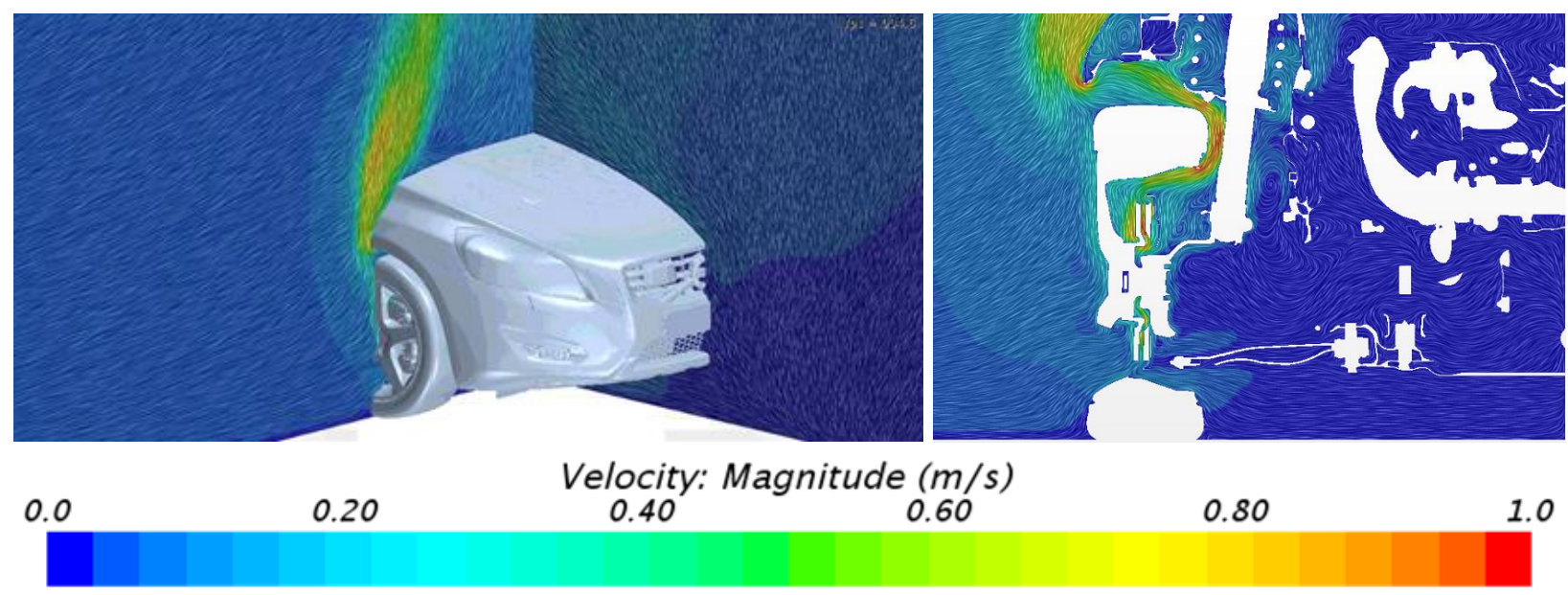

Figure 13. Natural convection velocity gradients in the beginning of the cool-down phase (1420 s)

One of the main benefits of the coupled setup is the way the heat flux is applied in-between the brake disc and the pads. Other methods may include heating up part of the brake disc by distributed volumetric flux or having fixed energy distribution between brake disc and the brake pads, but both of these approaches are unrealistic. The coupled method allows having a heat flux distribution that changes over time depending on part temperatures and material properties. This also means that there are no compromises required with the boundary conditions of the rotating disc surfaces, which usually cannot be set-up with incoming conduction heat flux and outgoing convection at the same time. Figure 14 shows the heat fluxes percentage distribution between disc and pads for the heat-up phase. It can be seen that, initially, all energy goes to the brake disc and later a balance is achieved with around $93.5 \%$ of energy going to the disc and the remaining $6.5 \%$ going into the pads. This matches well with the usual estimation of $5-10 \%$ and even better with other studies [22]. It can be seen that slightly less energy goes into the inner side of the disc, 
compared to the outer one, which happens due to faster heat-up of the inner surface of the disc that is protected by the brake shield.

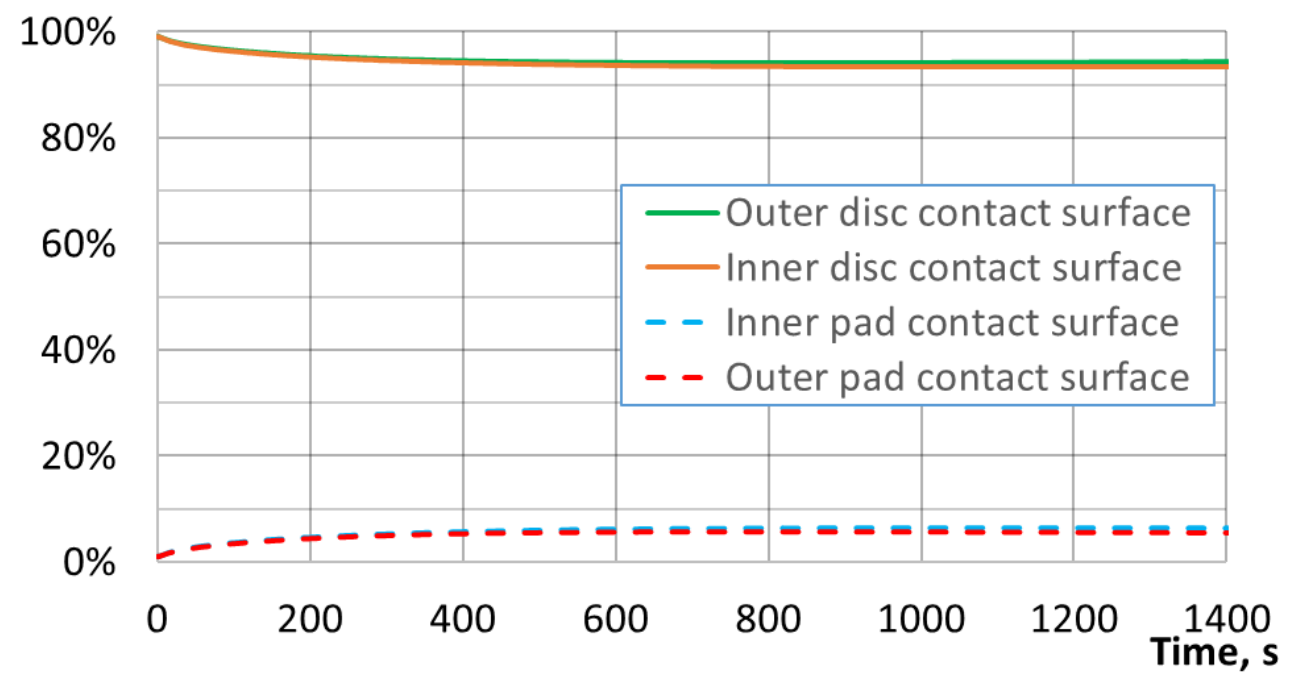

Figure 14. Heat fluxes from the contact between disc and pads changing during the heat-up phase

The changing relationship between different brake disc cooling mechanisms over time is presented in Figure 15. The convection curve behaviour is quite different for the two different phases of the cycle because the convection type switches from forced to natural after the vehicle is stopped. This mechanism of heat dissipation dominates while the vehicle is moving and, therefore, it will be investigated in more detail. Note that the wavy pattern on the convection curve is due to the coupling intervals selected for this specific case study.

To focus on energy dissipation, the conduction curve for the heat-up phase only includes the thermal energy transfer to the wheel rim and hub; while for the cool-down phase the energy transfer from the disc to the brake pads is also included. This adjustment explains a sudden increase in conduction values after the vehicle is stopped. It can be seen that for the heat-up phase a significantly smaller amount of energy is removed from the brake disc by conduction. However, after the vehicle is stopped it becomes the dominant mechanism of the energy dissipation. Further analyses showed that for both phases of the test the major part of energy transferred due to conduction goes into the wheel hub and the rim and not to the pads.

Compared to the other mechanisms, the contribution of radiation to cooling of the disc is considerably lower but not negligible. Furthermore, it can play a significantly greater role for other braking scenarios when the brake disc temperatures are higher. 


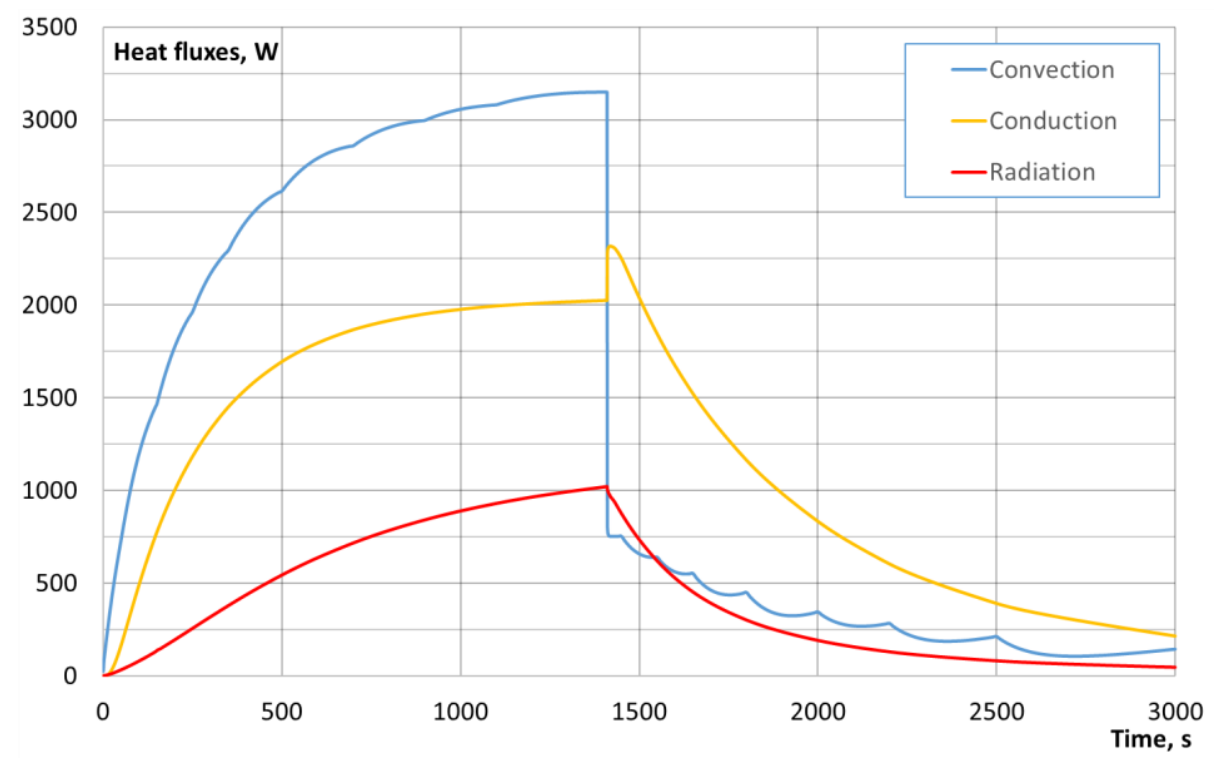

Figure 15. Cooling heat fluxes distribution for the brake disc

Since the convective heat transfer plays such an important role in the heat-up phase, it is interesting to look at the different brake disc surfaces, see Figure 16, and their contribution to this mechanism of heat transfer. This is depicted in Figure 17 where the importance of the inner vanes is obvious. The convection from the internal vanes at the end of the heat-up phase represents $53 \%$ of the total convective heat transfer from the brake disc surfaces. This value is in a good agreement with previous studies and can be even higher for faster rotational velocities [23]. In the case tested, the vane surfaces represented $40 \%$ of total surface area, but this value can be increased to $65 \%$ and above for larger discs, increasing the cooling capacity even further. The results show the importance of good vane design for brake cooling performance. Another interesting observation is that the inner contact surface is more efficient in heat dissipation the than outer surface, which also correlates well with other studies [14].

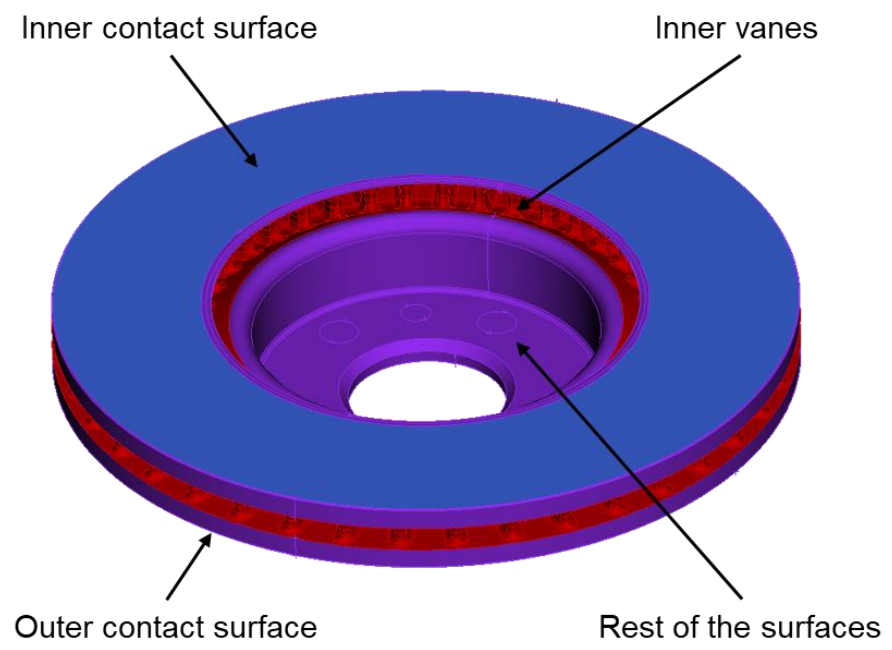

Figure 16. Brake disc surfaces partitioning for convection investigation 


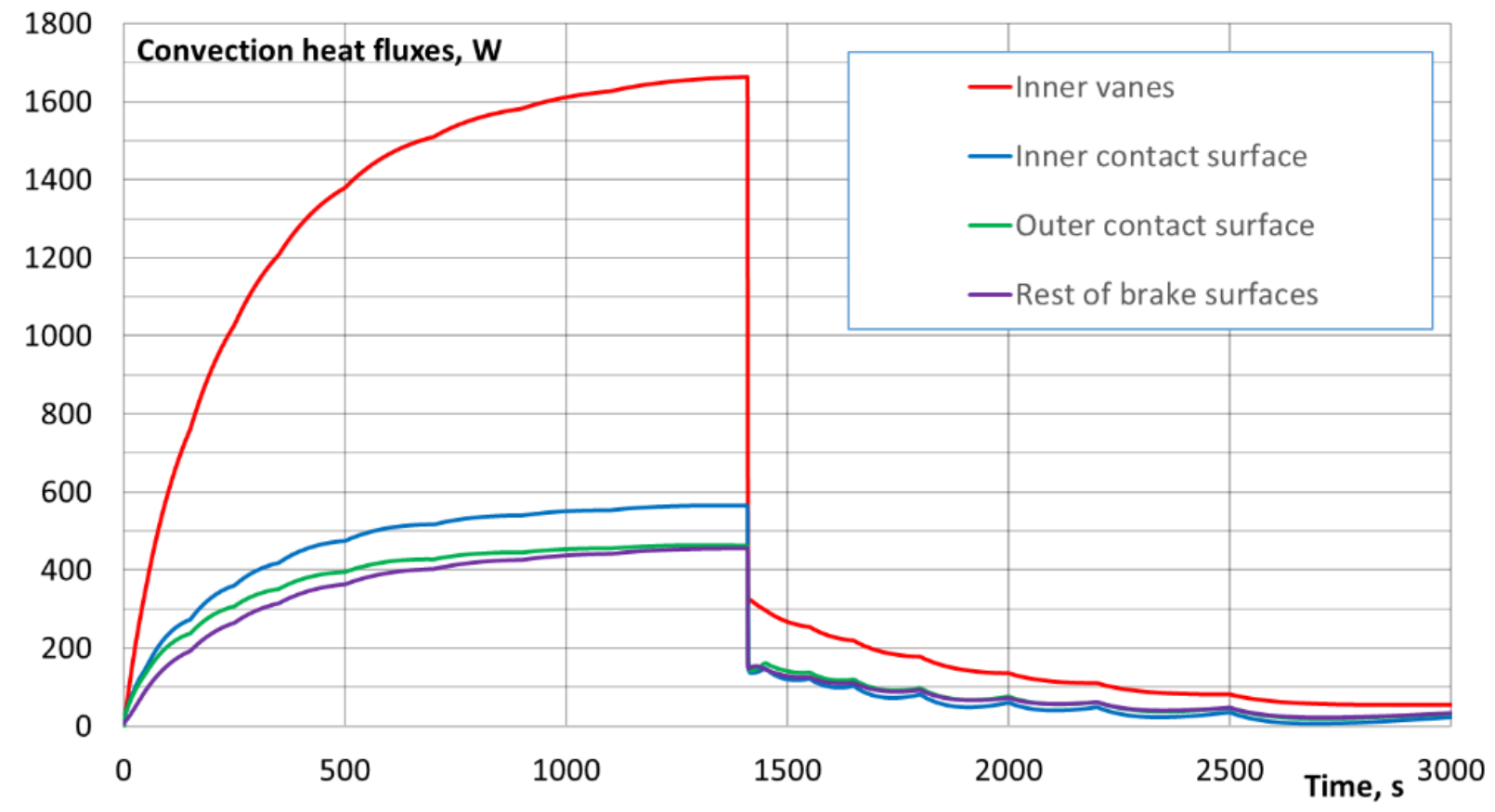

Figure 17. Convection distribution changing over time for different disc surfaces

\subsection{Other simulation cases}

Figures 18 and 19 show the differences in brake disc and brake fluid temperatures for the four investigated cases, namely: baseline, closed rim, blocked vanes and removed dust shield.

It can be seen from Figure 18 that blocking the brake disc vanes significantly increase the brake disc surface temperature; whereas Figure 19 shows that closing the rims has the largest effect on brake fluid temperatures, as it represents a considerably worse scenario compared to blocked disc vanes. This happens because the convection heat transfer for parts other than the brake disc, mainly the rim and the caliper, are significantly affected when the airflow through the rim is blocked. Moreover, since the brake fluid temperatures are more crucial for the brake system than the disc temperatures, a good rim design plays a vital role in good brake cooling performance.

In Figure 17, it was shown that the convection inside vanes of the brake disc is of high importance. The case study with blocked airflow through the vanes confirms again this finding by predicting the brake disc surfaces temperatures reaching a point around 100 degrees higher compared to the baseline case. The disc temperatures in this configuration are even slightly higher than for the case of blocked airflow through the rims. Nevertheless, due to better cooling of the other system components, the brake fluid temperatures are significantly lower.

Removing of brake shield gives a rather small benefit in terms of improving the cooling performance of the brake disc. However, it should be stated that instead of removing the shield it could be designed to guide the air to the surface of the disc and therefore improve the convection heat transfer from it when the vehicle is moving. 


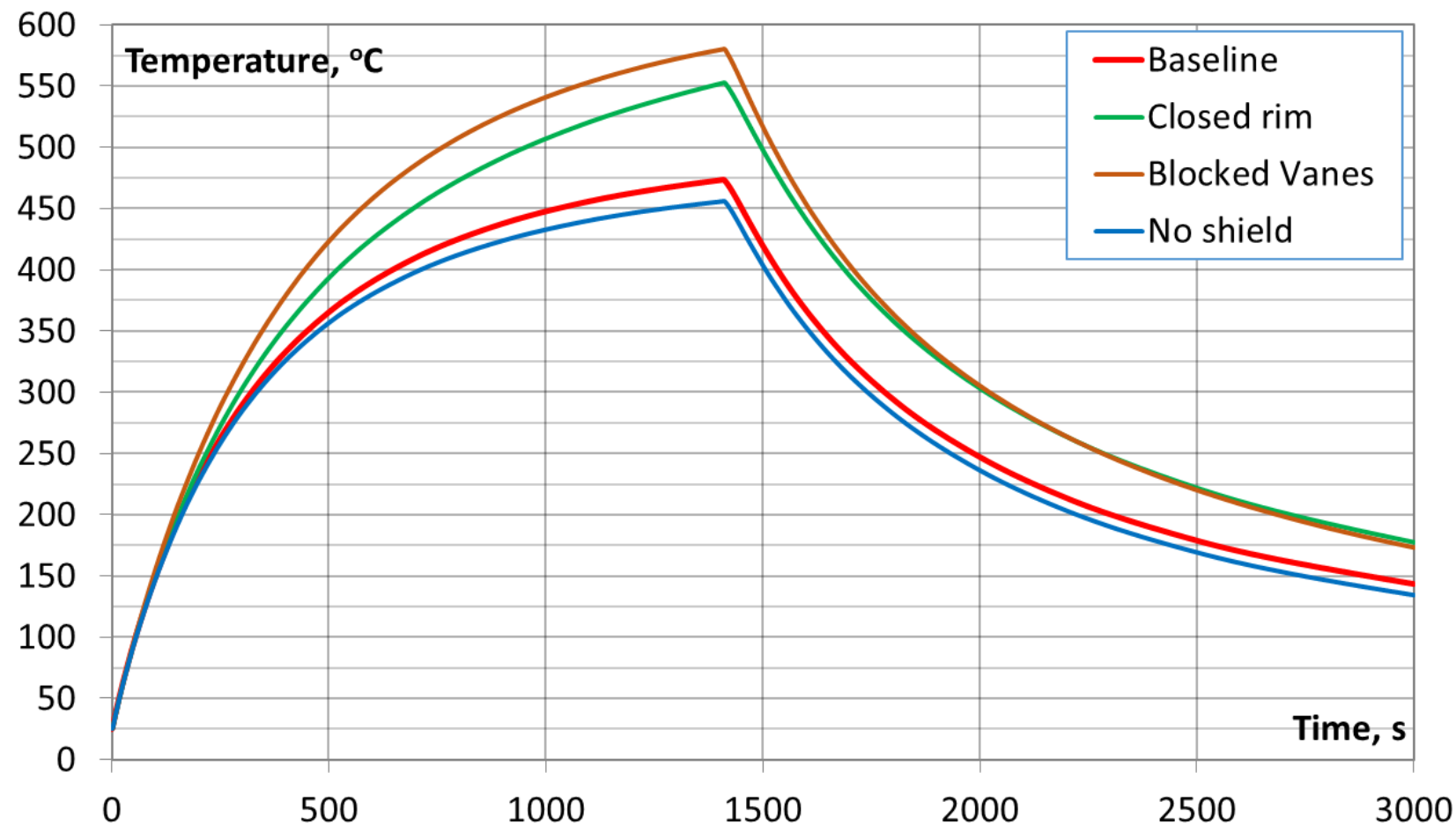

Figure 18. Brake disc temperature comparison (Point 1F) for investigated configurations

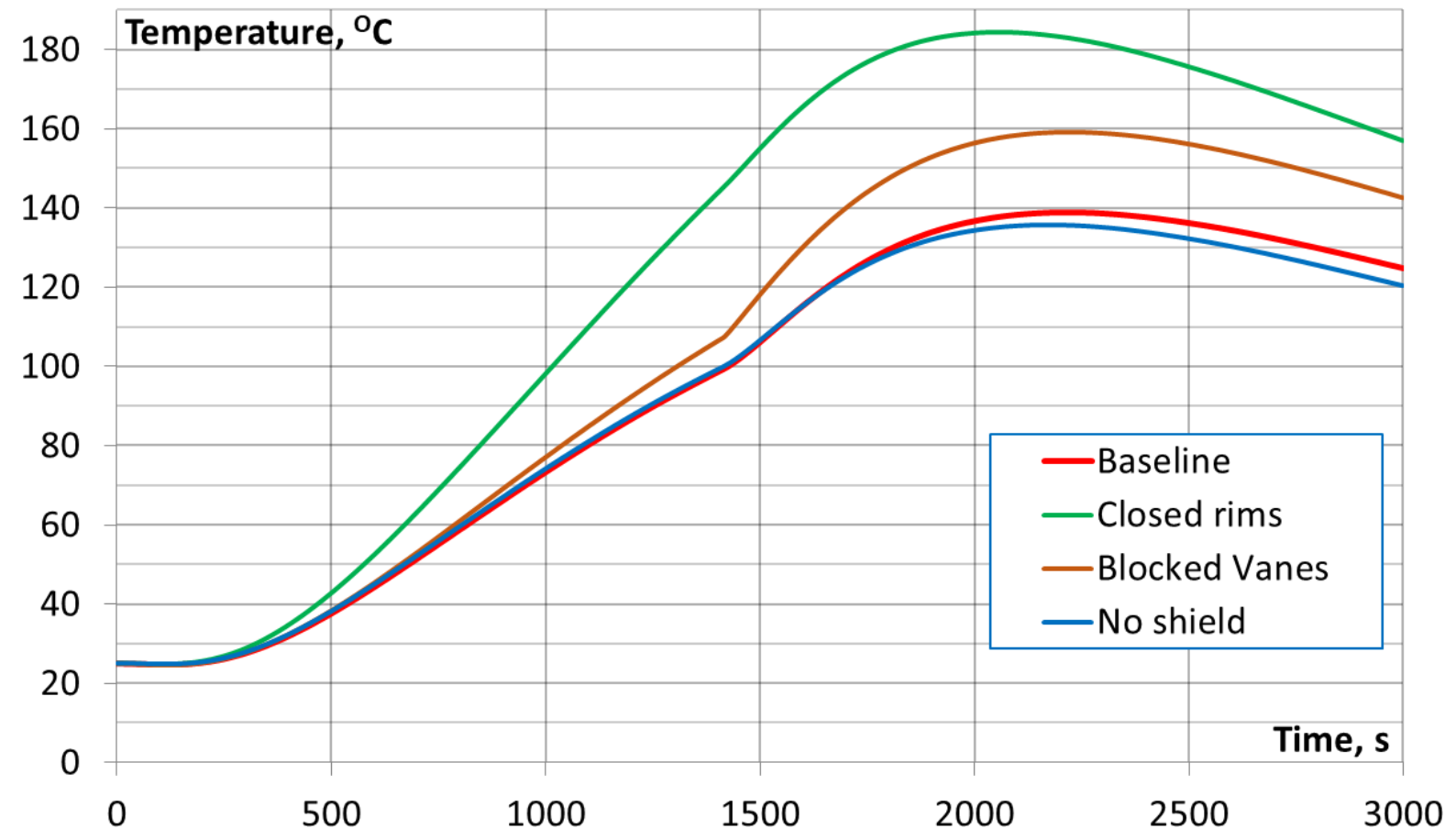

Figure 19. Brake fluid temperature comparison for investigated configurations 


\section{Conclusions}

Brake system operation modelling is a challenging task. Nevertheless, the study shows that with the use of a coupled procedure, good geometrical representation of the model and proper material data, it is possible to obtain satisfactory results. The procedure implemented in this work gives the benefit of performing virtual testing at early stages of the vehicle development when there are no prototypes available, or when prototyping is not possible.

Depending on the number of parts simulated, the procedure can be used to predict hot spots on parts that are not designed to work at high temperature, or just for better positioning of the thermocouples during the testing. Moreover, if test data is available, the procedure can be used to estimate the impact of various changes on the brake disc, brake fluid or other part temperatures.

The virtual model gives important insights into the temperature gradients within parts, something that could not be possible in experiments or the laboratory. It is becoming feasible to trace the heat fluxes within parts and from them, providing better understanding of heat transfer mechanisms and their roles for brake system. It was confirmed again that the convection, and especially convection from the vanes, is the most important mechanism of heat dissipation from the brake disc while the vehicle is moving. On the other hand, the brake disc temperatures are not as vital for the brake system compared to the brake fluid temperature that is also calculated. It is shown that while inefficient design of brake disc vanes can significantly increase the brake disc temperatures, the brake fluid temperature is much more affected by the general airflow inside the wheelhouse. An extreme case of closed rims, that is known to be beneficial from the aerodynamic drag perspective, resulted in a brake fluid temperature that is close to its boiling point. Hence, the trade-off between different vehicle requirements is challenging but essential and the option of simulating the brake performance tests in parallel with aerodynamic simulations is very valuable.

\section{Acknowledgements}

The authors would like to thank Volvo Car Corporation for the support of this study with special thanks to the Brakes department. In addition, ThermoAnalytics Inc. is acknowledged for technical support and providing test licenses for their software products.

\section{References}

[1] Stephens A., (2006), "Aerodynamic Cooling of Automotive Disc Brakes", MS Thesis, RMIT University. 
[2] Emery, A., F., Kumar, P., Firey, J., C., (1997), "Experimental Study of Automotive Brake System Temperatures”, Washington State Transportation Center, WA-RD 434.1.

[3] Michelin Tire Company, Michelin Truck Tire Service Manual, 2004.

[4] Ratamero, L. and Ferreira, R., "Wheel Cover Affected by the Heat Generated in the Brake System," SAE Technical Paper 2010-36-0380, 2010, doi:10.4271/2010-36-0380.

[5] Palmer, E., Mishra, R., Fieldhouse, J., and Layfield, J., "Analysis of Air Flow and Heat Dissipation from a High Performance GT Car Front Brake," SAE Technical Paper 2008-010820, 2008, doi:10.4271/2008-01-0820.

[6] G. Barigozzi, A. Perdichizzi and M. Donati, "Combined Experimental and CFD Investigation of Brake Discs Aero-thermal Performances," SAE Int. J. Passeng. Cars Mech. Syst., vol. 1, pp. 1194-1201, 2009.

[7] Yigit, S., Penther, P., Wuchatsch, J., and Werner, F., "A Monolithic Approach to Simulate the Cooling Behavior of Disk Brakes", SAE Int. J. Passeng. Cars - Mech. Syst. 6(3):14301437, 2013, doi:10.4271/2013-01-2046.

[8] G. Voller, M. Tirovic, R. Morris and P. Gibbens, "Analysis of automotive disc brake cooling characteristics", Proceedings of the Institution of Mechanical Engineers, Part D: Journal of Automobile Engineering, vol. 217, pp. 657-666, 2003.

[9] Amol V. More et al, "CFD Analysis of Automotive Ventilated Disc Brake Rotor", Int. Journal of Engineering Research and Applications, ISSN : 2248-9622, Vol. 4, Issue 4( Version 2), April 2014, pp.01-05.

[10] Stefan aus der Wiesche, "Heat transfer from a rotating disk in a parallel air crossflow", International Journal of Thermal Sciences, Volume 46, Issue 8, 2007, Pages 745-754, ISSN 1290-0729.

[11] Sun, H., "Sensitivity Study on Brake Cooling Performance," SAE Technical Paper 200601-0694, 2006, doi:10.4271/2006-01-0694.

[12] Jerhamre, A. and Bergström, C., "Numerical Study of Brake Disc Cooling Accounting for Both Aerodynamic Drag Force and Cooling Efficiency," SAE Technical Paper 2001-010948, 2001, doi:10.4271/2001-01-0948.

[13] Stephens, A., Watkins, S., and Dixon, C., "Aerodynamic Testing of a Vented Disc Brake," SAE Technical Paper 2003-01-0932, 2003, doi:10.4271/2003-01-0932.

[14] Schuetz, T., "Cooling Analysis of a Passenger Car Disk Brake," SAE Technical Paper 2009-01-3049, 2009, doi:10.4271/2009-01-3049.

[15] Bhambare, K., Haffey, M., and Jelic, S., "Brake Duty Cycle Simulation for Thermal Design of Vehicle Braking System," SAE Technical Paper 2013-36-0015, 2013, doi:10.4271/201336-0015.

[16] Palmer, E. and Jansen, W., "Development of a High Fidelity CAE Model for Predicting Brake System Temperatures," SAE Technical Paper 2017-01-0145, 2017, doi:10.4271/2017-01-0145.

[17] C. Desai, K. Vafai, "Three-dimensional buoyancy-induced flow and heat transfer around the wheel outboard of an aircraft", International Journal of Heat and Fluid Flow, Volume 13, Issue 1, 1992, Pages 50-64, ISSN 0142-727X. 
[18] CD-Adapco, StarCCM+ v12 user manual, 2017.

[19] ThermoAnalytics Inc., User Guide for TAITherm v12.3, 2017.

[20] Sternéus, J., Walker, T., and Bender, T., "Upgrade of the Volvo Cars Aerodynamic Wind Tunnel," SAE Technical Paper 2007-01-1043, 2007, doi:10.4271/2007-01-1043.

[21] G. Gigan, T. Vernersson, R. Lundén and P. Skoglund, "Disc brakes for heavy vehicles: an experimental study of temperatures and cracks," Journal of Automobile Engineering, vol. 229, no. 6, pp. 684-707, 2015.

[22] Talati, F. and Jalalifar, S., "Analysis of Heat Conduction in a Disk Brake System", Heat and Mass Transfer, V. 45, pp. 1047-1059, 2009.

[23] A.D. McPhee, D.A. Johnson, "Experimental heat transfer and flow analysis of a vented brake rotor", International Journal of Thermal Sciences, Volume 47, Issue 4, 2008, Pages 458-467, ISSN 1290-0729. 